\title{
Massive Formation of Equiaxed Crystals by Avalanches of Mushy Zone Segments
}

\begin{abstract}
A. LUDWIG, M. STEFAN-KHARICHA, A. KHARICHA, and M. WU
It is well known that the growth and motion of equiaxed crystals govern important microstructural features, especially in larger castings such as heavy ingots. To determine the origin of the equiaxed crystals, heterogeneous nucleation, and/or fragmentation of dendrite arms from columnar regions are often discussed. In the present study, we demonstrate that under certain conditions relatively large areas of mushy regions slide downward and form spectacular crystal avalanches. These avalanches crumble into thousands of dendritic fragments, whereby the larger fragments immediately sediment and the smaller proceed to behave as equiaxed crystals. Traces of such crystal avalanches can be seen by conspicuous equiaxed layers in the lower part of the casting. From the arguments in the discussion, it is believed that such a phenomenon may occur in alloys which reveal an upward solutal buoyancy in the interdendritic mush. This would include certain steels and other alloys such as $\mathrm{Cu}-\mathrm{Al}, \mathrm{Pb}-\mathrm{Sn}$, or Ni-Al-alloys. Moreover, the occurrence of crystal avalanches contribute to the formation of V-segregations.
\end{abstract}

DOI: $10.1007 / \mathrm{s} 11661-017-4008-\mathrm{y}$

(C) The Author(s) 2017. This article is published with open access at Springerlink.com

\section{INTRODUCTION}

MANY common alloys solidify by forming an outer equiaxed zone, followed by a columnar zone and a more-or-less extended inner equiaxed zone. ${ }^{[1,2]}$ The grains of the outer equiaxed zone form in contact with the mold wall by heterogeneous nucleation, and with the columnar dendritic zone by growth competition from the outer equiaxed zone. ${ }^{[3]}$ In the interior of the casting, equiaxed crystals form by either heterogeneous nucleation $^{[4]}$ or fragmentation of dendrites from the columnar zone. ${ }^{[5-7]}$ However, both mechanisms reveal same uncertainties. For instance, the origin of a heterogeneous site that reduces the energy barrier for nucleation is often unknown, especially for non-inoculated alloys. Conversely, the proposed criteria for the occurrence of fragmentation of dendrite arms ${ }^{[5,7]}$ can hardly be applied due to the complex overall interdendritic flow caused by forced or natural convection or deformation of the dendrite skeleton.

In the present study, observations are reported which show that relatively large areas of vertical columnar zones - especially at the upper part of the casting mold-may slide downward and form crystal avalanches. These avalanches consist of thousands of dendritic fragments from which equiaxed crystals grow. In the framework described above, this can be seen as substantial fragmentation and thus massive formation of equiaxed crystals.

\section{EXPERIMENTAL PROCEDURE}

A relatively large container $(0.6 \mathrm{~m}$ tall, $0.4 \mathrm{~m}$ wide and $0.06 \mathrm{~m}$ thick) was filled with a $29.6 \mathrm{wt}$ pet ammonium chloride - water solution. The given measures are internal dimensions. The lateral walls are made of brass, the bottom plate is made of aluminum, and the front and back walls are made of commercial PMMA (Polymethylmethacrylat) plates. The top of the cell was left open. The temperature of the brass walls was controlled via a circulation bath by applying an exponential cooling curve as $T(t)=T_{\alpha} \exp (-\alpha t)+T_{\text {inf. with }} T_{\alpha}=47 \mathrm{~K}, \alpha=0.033$, and $T_{\text {inf. }}=279 \mathrm{~K}\left(6^{\circ} \mathrm{C}\right)$. For the experiment reported in this work, we started with an alloy at a temperature of $T_{0}=325 \mathrm{~K}\left(52{ }^{\circ} \mathrm{C}\right)$, which was then cooled down to $T_{\text {inf. }}=279 \mathrm{~K}\left(6^{\circ} \mathrm{C}\right)$ via the side walls. Note that the interdendritic eutectic in the ammonium-water system forms at around $253 \mathrm{~K}\left(-15^{\circ} \mathrm{C}\right)$. Thus, even by reaching the minimal cooling temperature some interdendritic melt in the mushy zone remains liquid.

The ammonium chloride - water solution was prepared directly in the container by mixing ammonium chloride powder with distilled water at $325 \mathrm{~K}\left(52{ }^{\circ} \mathrm{C}\right)$. After the well-stirred alloying, we waited typically 1 hour to equilibrate the temperature field before cooling. During this time, the small, but continuous, heat loss through the front and back window resulted in a steady and symmetric thermal buoyancy flow which was used as the reproducible initial stage for the different experimental runs. ${ }^{[8]}$ After the equilibration time, cooling of the lateral and bottom walls was initiated.

\section{RESULTS}

In the experiments, solidification started by heterogeneous nucleation along the lateral and the bottom walls.

\footnotetext{
A. LUDWIG, M. STEFAN-KHARICHA, A. KHARICHA, and M. Chair for Simulation and Modelling of Metallurgical Processes, 8700 Leoben, Austria. Contact e-mail: ludwig@unileoben.ac.at Manuscript submitted August 12, 2016.

Article published online March 16, 2017
} 


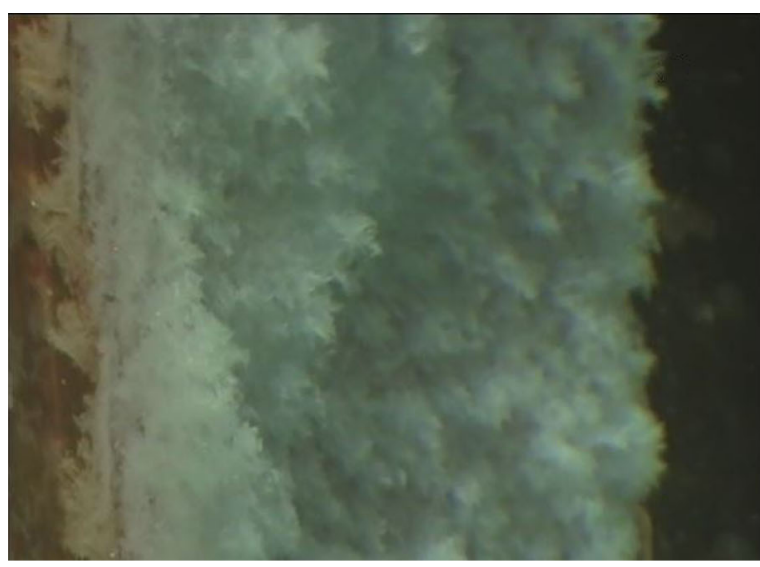

(a)

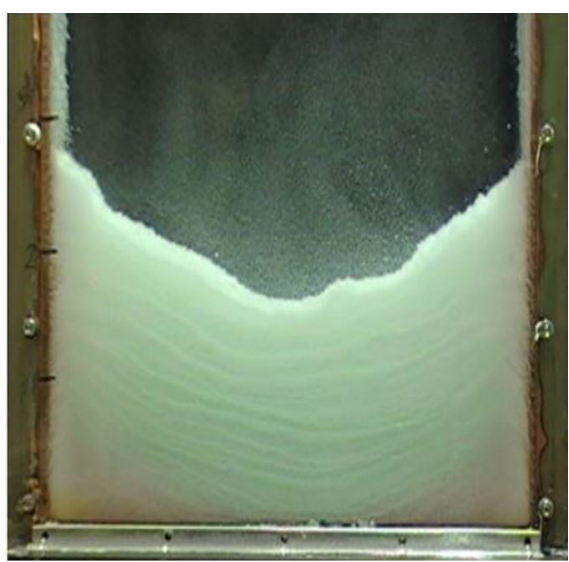

(b)

Fig. 1-(a) Mushy zone growing from the brass wall into the bulk melt. Note that the picture shows an inclined view of the 0.06-m-thick left brass wall. (b) Sedimented equiaxed crystals at the bottom of the 0.4-m-wide containment with around 15 traces of massive equiaxed formation due to repetitive occurrence of avalanches.

From those first crystals, visible dendritic structures grew more or less perpendicularly to the walls forming the columnar zone. Figure 1(a) shows the lateral brass wall covered with a mushy zone sticking to the brass mold surface. A clear influence of gravity on the dendrites' morphology and growth direction could not be observed. Additionally to the formation of the columnar dendrites, small equiaxed crystals exist in the bulk melt. As they grow in size, these crystals descend and sediment toward the bottom.

After the columnar zone has reached a certain thickness of 0.01 to $0.02 \mathrm{~m}$ occasionally parts of the columnar mushy zone, especially from the upper part of the containment, began to slide downwards. Within seconds the columnar mush disappeared, leaving behind a segment of the brass mold surface with only a thin layer of crystals. From this thin layer, columnar solidification started again, until eventually a new sliding event occurred. Fig. 2 shows a sequence of pictures taken with the time interval of $\Delta t=0.9$ seconds. In order to illustrate the sliding motion, we have marked two segments. The whole sliding process takes only a few seconds. Figure 3 shows the consequence: Crumbling of the sliding columnar area results in an avalanche of dendritic fragments whereby larger fragments immediately sediment and smaller proceed to behave as equiaxed crystals.

The sliding down parts of the mushy zone and the occurrence of such an avalanche of fragments is not a singular event. Rather in our experiments it happened repeatedly. Figure 1(b) shows corresponding traces of around 50 of such avalanches in the sedimented equiaxed bed. The first avalanche happened around 31 minutes after initial cooling, where the wall had a temperature of about $296 \mathrm{~K}\left(23{ }^{\circ} \mathrm{C}\right)$. From then on, avalanches occurred again and again from both side walls leading to a sedimentation trace of relative large dendritic fragments at the bottom of the container. However, every 5 to 6 minutes the avalanche activity diminished for a while, and descending of smaller equiaxed crystals from the bulk changed the appearance sedimentation traces. In Figure 1(b), recurring stages of lower avalanche activity leads to 15 sedimentation traces of finer equiaxed crystals. The avalanche presented in Figure 2 occurred around 92 minutes after initial cooling. At that time, the wall had nearly reached it minimal temperature of $279 \mathrm{~K}\left(6^{\circ} \mathrm{C}\right)$.

\section{DISCUSSION}

The ammonium chloride-water system forms a eutectic phase diagram ${ }^{[9]}$ with a eutectic concentration at $C_{\mathrm{E}}=19.7$ wt pet $\mathrm{NH}_{4} \mathrm{Cl}$. Thus, the ammonium chloride-water solution used for the reported experiments [29.57 wt pet $\mathrm{NH}_{4} \mathrm{Cl}$ with $\left.T_{\mathrm{L}}=310 \mathrm{~K}\left(37^{\circ} \mathrm{C}\right)\right]$ is a hyper-eutectic alloy, where ammonium crystals form on cooling. In consequence, the interdendritic liquid enriches in water and so its density decreases compared to the unsegregated bulk melt. This leads to a rising solutal interdendritic buoyancy flow as already observed and discussed in References 10 through 13.

For similar experiments in a smaller container $(0.1 \times$ $\left.0.1 \times 0.01 \mathrm{~m}^{3}\right)$, the present authors reported the occurrence of different flow regimes. ${ }^{[8,14,15]}$ Before solidification starts thermal buoyancy results in a downward flow along the cold lateral walls and a rising flow at the cell center. Such a flow pattern is also expected to occur in the present larger containment $\left(0.6 \times 0.4 \times 0.06 \mathrm{~m}^{3}\right)$. When solidification starts along the lateral and the bottom walls, solutal buoyancy leads first locally to a reversing of the flow. In References 8 and 15 this stage was called "perturbed thermal stage." The next stages following are the "turbulent flow stage" and the "coherent chaotic flow stage." In both stages, the main flow characteristics in the bulk melt were observed as being turbulent/chaotic but downward, so that in conclusion it can be stated that the interdendritic flow in the columnar mushy zone along the vertical walls was upwards. $^{[8,15]}$

In contrast to the geometrical constrains for the small containment used in References 8 and 15 the present 

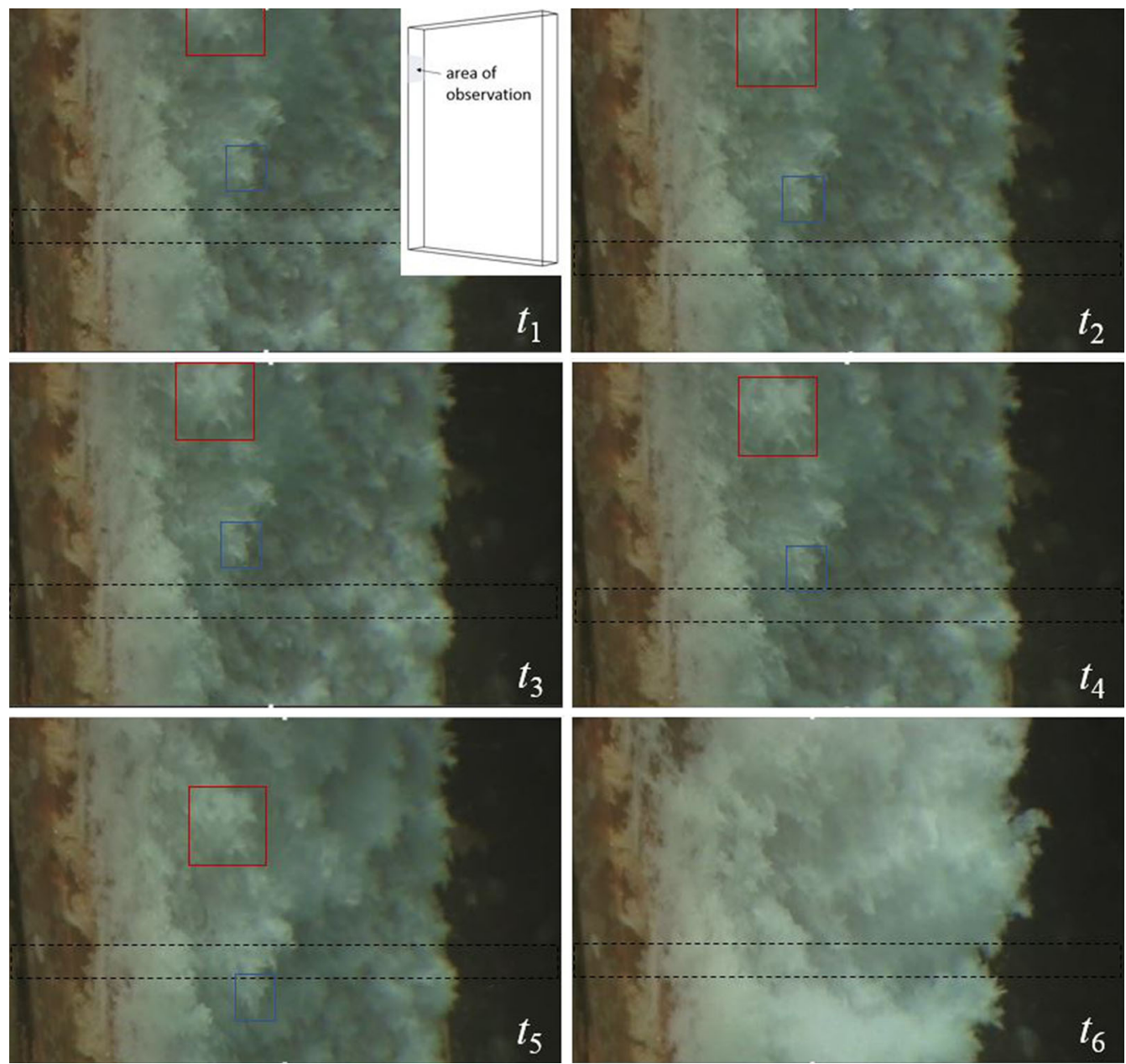

Fig. 2 - Sliding of a mushy zone segment. Pictures are taken at constant time interval of $\Delta t=0.9 \mathrm{~s}$. For improved visibility, two segments have been marked so that the motion can be followed. Note that the sliding started extremely slowly, so that pictures $t_{1}$ to $t_{3}$ look quite similar.

larger containment allows a relatively free development of solutal buoyancy flow-especially for the segregated interdendritic melt rising along the lateral walls. It is believed that this interdendritic flow results in an increase of the local microsegregation level in the upper part of the containment. Hence, there is melting of dendrite stems within the mushy zone and the overall mechanical stability diminishes. Obviously, the acting gravitational force due to the larger solid density compared to the liquid density exceeds the drag force from the upward flowing liquid, and so the whole mushy zone segment breaks and slips off.

A flow perpendicular to a horizontally solidifying dendritic mush would in principle not change the interdendritic microsegregation profiles. However, if the rising flow along the lateral walls has a horizontal component (as near the surface of the liquid where the global vortex turns away from the wall), slightly higher segregated melts is moving into areas of lower segregated melts. Due to the fact that for alloys, the thermal Prandtl number is much smaller than the solutal Prandtl number, the local temperature can be assumed to be approximately unaffected by the flow and thus solutal melting occurs.
It is also worth mentioning that the fact that the avalanche activity from time to time diminished reveals a certain unsteadiness of the flow. As reported in References 8 and 15 the overall flow pattern in such a solidification situation is generally turbulent even without avalanches. However, a detailed analysis of the corresponding flow pattern including a description of interdendritic melt flow and alteration of local microsegregation that leads to a local remelting is beyond the scope of the present report. However, from the discussion above, we can gather the following conditions for the appearance of such avalanches:

- The solid density must be sufficiently larger than the density of the melt.

- Interdendritic segregation must lead to a rising solutal buoyancy in vertical columnar mushy zone regions which should be stronger than any downwards thermal buoyancy flows.

- Global or even local vortices must deviate the rising solutal buoyancy flow to a horizontal direction.

- A relative broad mushy zone, which typically appear with small temperature gradients, must exist along the vertical wall. 


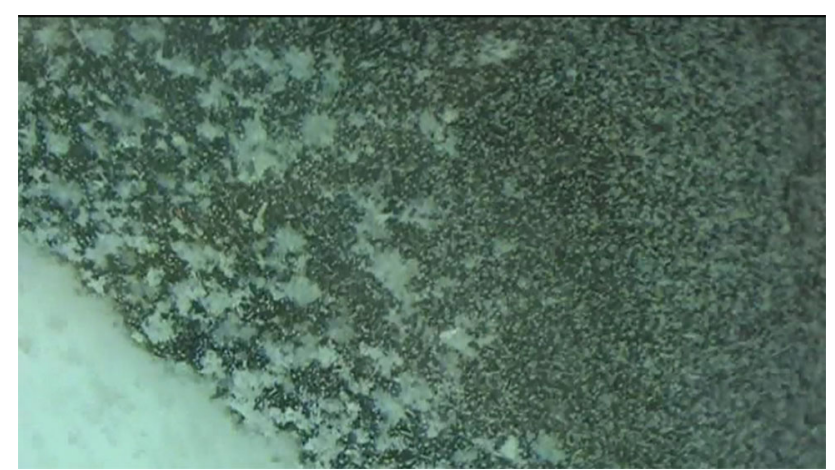

Fig. 3-Massive amount of crystal fragments that has formed only $16 \mathrm{~s}$ after a sliding down of a columnar area has started. Note that beside the larger fragments, the smaller fragments resemble the preexisting equiaxed crystals and can thus not be distinguished.

- The solidifying volume must be sufficiently large.

How relevant the described observation of crystal avalanches really is, cannot be answered easily. Especially during solidification of large steel ingots, the appearing microstructure is partly explained by the so-called "grain rain" phenomenon. ${ }^{[2]}$ Hereby, the grains are though to originate by hot-topping compound particle, nonmetallic inclusions, or dendrite fragmentations in such an amount that they form the well-known sedimentary cone at the bottom of the ingot. Furthermore, Kohn ${ }^{[16]}$ reported about an autoradiographic study of solidification on axial sections of killed steel ingots weighing from 1 to 30 tons. He stated on the formation of V-segregation: "It can be assumed that periodically the mound collapses and the crystals roll down to the bottom of the funnel, thus forming the alternating structure described above." Although in our experiment, the recurring $\mathrm{V}$-shaped sedimentation traces extend over the whole width of the mold, it is conceivable that avalanches of mushy zone segments are also contributing to the occurrence of $\mathrm{V}$-segregation in center regions of big steel ingots.

Finally, we would like to notice that although much progress had been made in modeling of ingot solidification $^{[2,17]}$ (nowadays the motion and growth of equiaxed crystals in the presence of columnar solidifying dendrites can even be modeled together with the formation of shrinkage cavities ${ }^{[18-22]}$ ), the presented phenomena is still far too complex for recent simulation models.

\section{CONCLUSIONS}

Parts sliding down from the vertically growing columnar mushy zone - especially from the upper part of the containment-lead to avalanches of dendritic fragments appearing. These fragments further behave similarly to equiaxed crystals. We thus think that the observed phenomena, especially as it happened repeatedly, may significantly contribute to the formation of the inner equiaxed zone in castings. We have discussed solutal melting of columnar dendrite stems, initiated by solutal buoyancy flow, as the likely origin of these sliding down of columnar arrays. Therefore, we expect such avalanches to appear for certain steels, $\mathrm{Cu}-\mathrm{Al}$, $\mathrm{Pb}-\mathrm{Sn}$, or Ni-Al-alloys, where it is known that rising interdendritic solute buoyancy flow exists. Especially, with the so-called 'hot topping,' often applied during ingot casting, relatively large columnar segments in the upper part of the casting may slide downward as the low temperature gradient results in relatively long columnar dendrites and obviously inward-turning vortices exit there. It is also possible that the described phenomenon contributed to the formation of $\mathrm{V}$-segregation in big steel ingots. The present report is a good example showing that solutal melting is quite important for the dynamic of solidification processes.

\section{ACKNOWLEDGMENT}

Open access funding provided by Montanuniversität Leoben. We kindly acknowledge the FWF (Austrian Science Fund, Grant Number P17619-N02 and P22614-N22) which paid the Ph.D. scholarship for Mrs. Stefan-Kharicha.

\section{OPEN ACCESS}

This article is distributed under the terms of the Creative Commons Attribution 4.0 International License (http://creativecommons.org/licenses/by/4.0/), which permits unrestricted use, distribution, and reproduction in any medium, provided you give appropriate credit to the original author(s) and the source, provide a link to the Creative Commons license, and indicate if changes were made.

\section{REFERENCES}

1. W. Kurz and D.J. Fisher: Fundamental of Solidification, 4th ed., Trans Tech Publications, Aedermansdorf, 1998.

2. W. Wołczyński: in The Encyclopedia of Iron, Steel, and Their Alloys, Taylor \& Francis Group, New York, 2016, pp. 1910-24.

3. Ch.-A. Gandin and M. Rappaz: Acta Metall., 1994, vol. 42, pp. 1133-46.

4. P. Thevoz, J.L. Desbiolles, and M. Rappaz: Metall. Trans. A, 1989, vol. 20, pp. 311-22.

5. T. Campanella, C. Charbon, and M. Rappaz: Metall. Mater. Trans. A, 2004, vol. 35A, pp. 3201-10.

6. R.H. Mathiesen, L. Arnberg, P. Bleuet, and A. Somogyi: Metall. Mater. Trans. A, 2006, vol. 37A, pp. 15-20.

7. A. Kumar and R. Dutta: J. Phys. D, 2008, vol. 41, pp. 155501-10.

8. A. Kharicha, M. Stefan-Kharicha, A. Ludwig, and M. Wu: $\mathrm{Me-}$ tall. Mater. Trans. A, 2013, vol. 44A, pp. 631-60.

9. T. Nishimura, T. Imoto, and H. Miyashita: Int. J. Heat Mass Transf., 1994, vol. 37, pp. 1455-64.

10. C. Beckermann and R. Viskanta: Int. J. Heat Mass Transf., 1988, vol. 31 , pp. 2077-89.

11. C. Beckermann and R. Viskanta: Chem. Eng. Commun., 1989, vol. 85 , pp. $135-56$.

12. D.G. Neilson and F.P. Incropera: Int. J. Heat Mass Transf., 1991, vol. 34, pp. 1717-32.

13. D.G. Neilson and F.P. Incropera: Int. J. Heat Mass Transf., 1993, vol. 36, pp. 489-505. 
14. A. Kharicha, M. Stefan-Kharicha, M. Wu, and A. Ludwig: IOP Conf. Ser. Mater. Sci. Eng., 2012, vol. 33, p. 12115.

15. M. Stefan-Kharicha, A. Kharicha, M. Wu, and A. Ludwig: Fluid Dyn. Res., 2014, vol. 46, p. 41424.

16. A. Kohn: in Int. Conf. Solidif. Cast. 1. London Inst. Met., 1977, pp. $356-62$.

17. A. Ludwig, M. Wu, and A. Kharicha: JOM, 2016, vol. 68, pp. 2191-97.
18. M. Wu and A. Ludwig: Acta Mater., 2009, vol. 57, pp. 5621-31.

19. M. Wu and A. Ludwig: Acta Mater., 2009, vol. 57, pp. 5632-44.

20. M. Wu, A. Fjeld, and A. Ludwig: Comput. Mater. Sci., 2010, vol. 50 , pp. $32-42$.

21. M. Wu, A. Ludwig, and A. Fjeld: Comput. Mater. Sci., 2010, vol. 50 , pp. $43-58$.

22. M. Ahmadein, M. Wu, J.H.H. Li, P. Schumacher, and A. Ludwig: Metall. Mater. Trans. A, 2013, vol. 44A, pp. 2895-2903. 